- $77.1 \%$ of patients missed at least one of their follow-up visits planned at 1, 3 and 6 months after PEP start, and

- no case of seroconversion was observed.

Conclusion Approximately equal numbers of sexes seek counselling service for PEP. Most prevalent types of exposure include high risk sexual contact and needlestick injuries. Lopinavir/ritonavir with tenofovir/emtricitabine combination seems to be a well tolerated and effective therapy.

\section{P4.050 "YOU CAN IGNORE US BUT WE WON 'T GO AWAY": A QUALITATIVE STUDY TO EXPLORE SEXUAL EXPERIENCES AND VULNERABILITY TO HIV INFECTION AMONG LESBIAN, BISEXUAL, TRANSGENDER AND INTERSEX WOMEN IN BULAWAYO, ZIMBABWE}

doi:10.1136/sextrans-2013-051184.0948

\begin{abstract}
H M Ndondo, S Maseko, S Ndlovu. Sexual Rights Centre, Bulawayo, Zimbabwe
\end{abstract}
Background The vulnerability of lesbian, bisexual, transgender and intersex (LBTI) women to HIV infection is a complicated public health issue that remains poorly documented. The Zimbabwe National AIDS Strategic Plan 2011-2015 does not acknowledge LBTI women as a vulnerable population for HIV infection. This study sought to explore sexual experiences and HIV risk behaviour among LBTI women and to determine challenges and experiences of accessing HIV services.

Methods Three focus group discussions were conducted with LBTI women aged 18 years and above, $n=29$. Purposive sampling was used to recruit study participants through announcements at relevant meetings and safe spaces in Bulawayo. Focus group discussions were digitally recorded and transcribed verbatim. Using ATLAS. ti software, a set of a priori concept-driven codes were applied to the transcripts. The analysis concentrated on HIV risk perception, sexual behaviour and access to health services, experiences of violence, stigma and discrimination.

Results Participant's perception of HIV risk was very low despite their engagement in sexual activities that involve sharing of body fluids. Narratives revealed that the majority of LBTI women never practised safe-sex, lacked awareness of the existence of LBTI specific protective measures against HIV and rarely sought HIV counselling and testing services. LBTI women reported experiencing a repertoire of social exclusion and violence in their lives including forced sexual experiences. Barriers to HIV care and support, included HIV-related stigma, hetero-normative assumptions in HIV and STI related health services and unprofessional, discriminatory and incompetent treatment by health professionals.

Conclusions HIV risk among LBTI women is elevated by lack of access to HIV prevention services and barriers to HIV care and support. This study highlights a trajectory of structural exclusion of LBTI women which accentuates their vulnerability to HIV infection. HIV/AIDS policy in Zimbabwe should address HIV prevention, care and support for LBTI women.

\section{P4.051 VULNERABILITY TO HIV AND PREVENTION NEEDS OF FEMALE POST-SECONDARY STUDENTS ENGAGED IN TRANSACTIONAL SEX IN KUMASI, GHANA - A QUALITATIVE STUDY}

doi:10.1136/sextrans-2013-051184.0949

${ }^{1} \mathrm{M}$ Baba-Djara, ${ }^{2} \mathrm{~T}$ Agyarko-Poku, ${ }^{3} \mathrm{~K}$ Baffuor Opoku, ${ }^{1} \mathrm{P}$ G Ashigbie, ${ }^{1} \mathrm{~A}$ Breman, ${ }^{1} \mathrm{C}$ Corneliess, ${ }^{4} \mathrm{~K}$ Akuoko, ${ }^{1} \mathrm{~J}$ Beard, ${ }^{5} \mathbf{Y}$ Adu-Sarkodie. ' $\mathrm{C}$ Center for Global Health and Development, Boston University, Boston, MA, United States; ${ }^{2}$ Suntreso Hospital, Ghana Health services, Kumasi, Ghana; ${ }^{3 K}$ Komfo Anokye Teaching Hospital, Kumasi, Ghana; ${ }^{4}$ Ghana Health Service, Kumasi, Ghana; ${ }^{5}$ Kwame Nkrumah University of Science and Technology School of Medicine, Kumasi, Ghana
Background This was a qualitative study on the vulnerability to HIV of female post-secondary students engaging in transactional sex (TS) - defined as engaging in sex for the purpose of obtaining material goods, financial support, or grades, not including commercial sex work - in Kumasi, Ghana. While little is known about TS among students in Ghana, sub-Saharan African women with postsecondary education often have a higher HIV prevalence than those with secondary school education only. The objective of this study is to better understand motivations to engage in TS, the types of transactional sex, their partners, and their HIV/AIDS prevention needs.

Methods Data was collected at three post-secondary institutions in Kumasi using in-depth interviews with female post-graduate students (aged 18 to 25), and focus group discussions with female and male students (aged 18 to 25). Key informant interviews were conducted among faculty, residence hall matrons, and local hotel staff. Participants for in-depth and key informant interviews were recruited through snowball sampling.

Results Transactional sex appears to be quite common in postsecondary settings, and the men involved are older and financially stable. The drivers of TS include familial poverty, financial need, peer pressure, desire for luxury or fame and desire for good grades.

Participants reported inconsistent condom use with partners and identified unwanted pregnancy, mental turmoil from abortion, HIV, and other sexually transmitted infections as risks associated with TS. Risky behaviours identified included unprotected sex, multiple sexual partners, and age-disparate relationships. Participants were unfamiliar with institutional policies on reporting TS and expressed lack of confidence in the system. Students also reported little confidence in the reproductive and health services available to them.

Conclusion Transactional sex involves high risk behaviours for HIV infection. Further research is needed to explore the extent of TS and HIV prevalence and risk among post-secondary students

\section{P4.052 LOW LEVEL OF AWARENESS LEADING TO STIGMA TOWARDS PERSONS WITH HIV/AIDS}

doi:10.1136/sextrans-2013-051184.0950

A Muhammad. Global Funds/TB Control Program, Islamabad, Pakistan

Aim HIV thrives among mobile populations. Truck drivers particularly the long distance truck drivers are more vulnerable to HIV infection, because they travel a lot, remain cut off from the mainstream society, often engage in activities such as having unsafe sex with commercial sex workers and fellow crew members, in order to reduce their loneliness.

Methods In this study Interviews of 75 truck drivers at Badami Bagh Truck Stand, Lahore, Pakistan, were carried out on non-random basis, using convenient sampling technique through a structured questionnaire The objective was to assess link between level of knowledge about HIV/AIDS and the attitude towards persons with AIDS.

Results $50 \%$ of the truck drivers were found unaware about the role of needles as a means of spreading HIV/AIDS. 30-40\% thought that needles had nothing to do with the transmission of AIDS Forty to fifty percent of respondents had the misconception that AIDS can be contracted by casual contact and by being in the same room with a person with AIDS. Two third of the truck drivers were of the view that monogamy and condom use is an effective method for AIDS prevention. An association between low knowledge of AIDS and high negative attitude towards persons with AIDS was found to exist, which was statistically significant.

Conclusion Long distance truck drivers in Pakistan have serious gaps in their knowledge about HIV/AIDS, especially its modes of transmission, signs/symptoms and prevention. Stigma towards persons with AIDS also exists due to Low level of knowledge about HIV/AIDS 